\title{
PREVALENCE OF POTENTIALLY REVERSIBLE DEMENTIAS IN A DEMENTIA OUTPATIENT CLINIC OF A TERTIARY UNIVERSITY-AFFILIATED HOSPITAL IN BRAZIL
}

\author{
Leonel Tadao Takada ${ }^{1}$, Paulo Caramelli2, Marcia Radanovic ${ }^{3}$, \\ Renato Anghinah", Ana Paula B. J. Hartmann ${ }^{4}$, Carla Cristina Guariglia ${ }^{4}$, \\ Valéria Santoro Bahia ${ }^{4}$, Ricardo Nitrini ${ }^{5}$
}

\begin{abstract}
The importance of investigating the etiology for dementia lies in the possibility of treating potentially reversible dementias. The aims of this retrospective study are to determine the prevalence of potentially reversible dementias among 454 outpatients seen at the Cognitive and Behavioral Neurology Unit, Hospital das Clínicas, São Paulo University School of Medicine - Brazil, between the years of 1991 and 2001, and observe their evolution in follow-up. Among the initial 454 patients, 275 fulfilled the DSM-IV criteria for dementia. Alzheimer's disease was the most frequent diagnosis (164 cases; 59.6\%). Twenty-two cases (8.0\%) of potentially reversible dementia were observed, the most frequent diagnoses being neurosyphilis (nine cases) and hydrocephalus (six cases). Full recovery was observed in two patients and partial recovery in 10 patients. Two cases were not treated and eight cases were lost on follow-up. The prevalence found in the present study falls within the range reported in previous studies (0-30\%).
\end{abstract}

KEY WORDS: dementia, prevalence, Alzheimer's disease, neurosyphilis, hydrocephalus.

\section{Prevalência de demências potencialmente reversíveis em ambulatório especializado de hospital universitário terciário no Brasil}

RESUMO - A importância de se investigar a etiologia da demência encontra-se na possibilidade de se tratar demências potencialmente reversíveis. Os objetivos deste estudo retrospectivo são determinar a prevalência de demências potencialmente reversíveis em 454 pacientes atendidos no Grupo de Neurologia Cognitiva e do Comportamento do Hospital das Clínicas da Faculdade de Medicina da Universidade de São Paulo entre 1991 e 2001 e observar a sua evolução em seguimento. Entre os casos iniciais, 275 preencheram os critérios de demência do DMS-IV. Doença de Alzheimer foi o diagnóstico mais freqüente (164 casos; 59,6\%). Vinte e dois casos $(8,0 \%)$ de demência potencialmente reversível foram encontrados, sendo os diagnósticos mais freqüentes neurossífilis (nove casos) e hidrocefalia (seis casos). Recuperação completa após tratamento foi observada em dois pacientes e parcial, em dez. Dois pacientes não receberam tratamento eoito não aderiram ao seguimento. A prevalência encontrada neste estudo situa-se entre as relatadas em estudos anteriores (0-30\%).

PALAVRAS-CHAVE: demência, prevalência, doença de Alzheimer, neurossífilis, hidrocefalia.

According to Maletta ${ }^{1}$, the concept of reversible dementias, as it has been most frequently understood, covers three groups of distinct conditions. The first one consists of depression with associated cognitive impairment, which is often referred to as "pseudodementia". The second group comprisesis made of conditions which more commonly cause acute confusional states or delirium, such as toxic and metabolic disturbances. The third group of reversible dementias is composed of conditions such as normal pressure hydrocephalus or neurosyphilis, also referred to as secondary dementias (as opposed to primary dementias such as Alzheimer's disease) or disease-specific dementias. The third group embodies reversible dementias as they are most widely accepted. The first problem encountered when trying

Behavioral and Cognitive Neurology Unit, Department of Neurology, Hospital da Clínicas, University of São Paulo School of Medicine (USP) São Paulo SP, Brazil: ${ }^{1}$ Undergraduate Student, USP; ${ }^{2}$ Assistant Professor, USP; ${ }^{3}$ Consultant Neurologist, USP; ${ }^{4}$ Postgraduate Student, USP; ${ }^{5}$ Associate Professor, USP.

Received 16 April 2003. Accepted 1 August 2003.

Dr. Leonel Tadao Takada - Rua Dr. Mário Cardim 87 - 04019-000 São Paulo SP - Brazil. E-mail: Ittakada@ hotmail.com 
to identify the prevalence of potentially reversible dementias is the lack of consistent definitions for of potentially reversible causes of dementia acrossamong various studies ${ }^{2}$. For instance, depression may have been considered a treatable dementia in earlier studies ${ }^{2-5}$. However, thisit may not fulfill the current criteria for dementia 4 .

The prevalence of potentially reversible dementias has previously been reported by several authors, and the results have varied widely among studies ${ }^{2-10}$. One of the first studies on potentially reversible dementias is that of Marsden \& Harrison ${ }^{11}$, in which 27 out of 108 patients presented potentially reversible dementias. Clarfield ${ }^{3}$, in an meta-analysis of 32 studies, found that the prevalence of potentially reversible dementias was $13.2 \%$ (ranging from 0 to $32.5 \%$ ). The most frequent causes found were drugs, depression and metabolic disturbances. Barry and Moskowitz $^{2}$ found the prevalence of treatable conditions to rangeranging from $1.3 \%$ to $30 \%$, while reviewing 10 studies between theyears of 1972 and 1986. Weything ${ }^{4}$, in a quantitative review of 16 studies published between 1972 and 1994, found that $15.2 \%$ was the prevalence of potentially reversible causes of dementia. The most frequent causes found were again depression and drug intoxication. The prevalence of potentially reversible dementias in Brazil has previously been shown in three studies. One ${ }^{12}$ indicated a prevalence of potentially reversible dementias of $23.6 \%$. Of these, $2.7 \%$ had partially reversible dementia and $1.8 \%$ had fully reversed dementia after treatment of the underlying disease. The most frequent cause of potentially reversible dementia was low serum vitamin B12 dosage. In a previous study within our outpatient unit ${ }^{7}$, eight out of 100 patients presented potentially reversible causes of dementia, which were hydrocephalic dementia (six cases, four of which had normal pressure hydrocephalus) and neuroshyphilis (two cases). Vale and Miranda ${ }^{9}$ found, among 186 patients, potentially reversible causes of dementia in 32 cases (16 cases of alcoholism, 10 cases of normal pressure hydrocephalus, 4 cases of neurosyphilis and two cases of depression).

The importance of investigating potentially reversible dementias and determining its prevalence lies not only in the obvious opportunity to lessen one's cognitive impairment by treating the underlying cause of such a condition, but also in the decision of how to investigate such dementias. Given that the pretest probability of potentially reversible dementia is high or low, one must consider the costbenefit of each test and the burden those tests would bring to the patients, should a broader diagnostic approach to dementia be used, and also the probability of the occurrence of false positive tests ${ }^{2,4}$.

The actual reversibility of potentially reversible dementias has been reviewed in studies by Clarfield $^{3}$ and Weytingh et al. ${ }^{4}$ Clarfield $^{3}$ found that, in 11 studies, $11 \%$ of the cases of such dementias showed improvement after treatment (8\% with partial recovery and $3 \%$ with complete recovery). Weytingh et al. ${ }^{4}$, found partial reversal to range from 0 to $23 \%$ of dementia cases (average 9.3\%) and full reversal ranging from 0 to $10 \%$ (average $1.5 \%$ ). It was also observed that partially and fully reversed dementia cases haves fallen over the past few years, and therefore augmenting the discussion over an adequate approach to dementia.

The aim of this study is to ascertain the prevalence of potentially reversible dementias in the Behavioral and Cognitive Neurology Unit from the division of Neurology, at the Hospital das Clínicas of the University of São Paulo School of Medicine, Brazil (USP), a clinic dedicated to patients with cognitive impairment, by retrospectively studying the cases of outpatients seen over ten years' of experience (19912001), as well as observing the evolution of potentially reversible dementia cases in follow-up.

\section{METHOD}

We retrospectively reviewed the files of 454 outpatients consecutively seen consecutively in the USP Cognitive and Behavioural Neurology Unit over the period 1991 to 2001 period.

The patients' clinical evaluation included complete clinical history and physical/neurological examination along with cognitive evaluation. A laboratory evaluation was also performed and included complete blood count, serum sodium and potassium, urea, creatinine, cholesterol, tryglicerides, uric acid, calcium, phosphorus, total protein, albumin, globulin, bilirubin, alkaline phosphatase, $\gamma$-glutamyl transferase, transaminases concentrations, erythrocytesedimentation rate, serum thyroxine, $T_{3}$ and thyroid-stiymulating hormone concentrations, serum VDRL and FTA-ABS and computed tomography or magnetic resonance imaging of the head. Other tests were performed based on the diagnostic hypothesis considered for each case.

The diagnosis of dementia was based on the Diagnostic and Statistical Manual of Mental Disorders - Fourth Edition $(D S M-I V)^{13}$ criteria for dementia. The diagnosis of Alzheimer's disease (possible or probable) was made according to the National Institute of Neurological and Communicative Disorders and Stroke - Alzheimer Disease and Related Disorders Association (NINCDS-ADRDA) ${ }^{14}$ criteria. The diagnosis of definite Alzheimer's disease was achieved as a post mortem diagnosis (when an autopsy was performed). The diagnosis of vascular dementia followed the National Institute of Neurological Diseases and Stroke - Association 
Internationale pour la Recherche et I'Enseignement en Neurosciences (NINDS-AIREN) ${ }^{15}$ criteria of probable and possible vascular dementia.

The criteria used in the diagnosis of dementia with Lewy bodies was that of the consortium on DLB consensus guidelines ${ }^{16}$. Frontotemporal dementia was reached fromachieved as a diagnosis based on the modified Lund Manchester criteria ${ }^{17}$. Parkinson's disease with associated dementia was diagnosed when parkinsonian syndrome was more, or as, evident as the dementia syndrome. The diagnosis of depression was based on the Diagnostic and Statistical Manual of Mental Disorders - Fourth Edition ${ }^{13}$ criteria on depressive disorder. Other diagnoseis were made based on usual criteria.

The observation of improvement (or lack of) in each case was made based on clinical impression when data were available. When data were lacking, patients and/or families were contacted bythrough telephone and the cognitive outcome was obtained fromby their impressions.

The analysis of the data obtained was made utilizingthrough the program SPSS for Windows version 10.0.1.

\section{RESULTS}

Two hundred and seventy five patients fulfilled the criteria for the diagnosis of dementia. Of these, 79 had already been included in a former report ${ }^{7}$. Among the remaining 179 that did not have dementia, depression was diagnosed in 31 individuals.

Alzheimer's disease (AD) was the most frequently established diagnosis (Table 1). Among the 164 cases of $A D$, the diagnosis of definite $A D$ was made in four cases. Probable AD was found in 95 cases, whereas 65 cases of possible AD were encountered. The second most frequent diagnosis was that of vascular dementia (VD). Probable VD was the final diagnosis in five cases; the other 32 individuals being considered to be possible VD cases (hydrocephalus was found as a comorbidity in one case of possible VD). In 20 cases, no specific etiology for dementia could be established. Other diagnoseis made are enlisted in Table 1.

In the present study, neurosyphilis, hydrocephalus, alcoholic dementia, Wernicke-Korsakoff syndrome, Wilson's disease and subdural hematoma were considered potentially reversible causes of dementia, thus totaling $22(8.0 \%$ of all cases with dementia and $4.8 \%$ of all patients seen) patients in the potentially reversible dementia group. The two most frequent diagnoses in this group were neurosyphilis (nine cases) and hydrocephalus (six cases). Hydrocephalus was alson found as a comorbidity in 2 cases (1 with possible VD previously described and one with neurosyphilis).

The potentially reversible dementia group has its demographical characteristics (age and schooling years) listed in Table 2 . The gender distribution was as follow: three female and 22 male. Table 2 are also listsed the characteristics found for the irreversible dementia group, which was composed of 147 females and 105 males. The groups were different concerning on gender ( $p \sim 0$, Chi-Square test), as there were more male patients in the reversible dementia group. No statistically significant differences were found between the groups when schooling years were considered $(p=0.065$, MannWhitney $U$ test), but a significant difference was found in age between the groups ( $p \sim 0$, Mann-Whitney $U$ test). The potentially reversible dementia group had a lower mean age mean than the irreversible

Table 1. Etiology of dementia.

\begin{tabular}{|c|c|c|}
\hline Etiology of Dementia & $\mathrm{N}$ & Percentage (\%) \\
\hline Alzheimer's disease & 164 & 59.6 \\
\hline Vascular dementia & 37 & 13.4 \\
\hline Frontotemporal dementia & 14 & 5.1 \\
\hline Neurosyphilis & 9 & 3.3 \\
\hline Dementia with Lewy Body & 6 & 2.2 \\
\hline Hydrocephalus & 5 & 1.8 \\
\hline Parkinson's disease & 4 & 1.5 \\
\hline Alcoholic dementia & 3 & 1.1 \\
\hline Creutzfeldt-Jakob disease & 3 & 1.1 \\
\hline Wernicke-Korsakoff & 3 & 1.1 \\
\hline Huntington's disease & 2 & 0.7 \\
\hline Wilson's disease & 1 & 0.4 \\
\hline Dementia due to head trauma & 1 & 0.4 \\
\hline Subdural hematoma & 1 & 0.4 \\
\hline Multiple System Atrophy & 1 & 0.4 \\
\hline Progressive supranuclear palsy & 1 & 0.4 \\
\hline Undetermined & 20 & 7.3 \\
\hline Total & 275 & 100 \\
\hline
\end{tabular}

Table 2. Comparison between groups for age and schooling years.

\begin{tabular}{lcc}
\hline & $\begin{array}{c}\text { Potentially reversible } \\
\text { dementias }\end{array}$ & $\begin{array}{c}\text { Irreversible } \\
\text { dementias }\end{array}$ \\
\hline Age & 53.86 (SD 13.97) & 68.95 (SD 9.66) \\
$\begin{array}{l}\text { Schooling } \\
\text { years }\end{array}$ & 7.33 (SD 5.52) & 5.26 (SD 4.29) \\
\hline
\end{tabular}


dementia group. There were 23 illiterates in the irreversible dementia group and one illiterate in the potentially reversible dementia group.

Among the patients in the potentially reversible dementia group, full recovery was observed in two patients (one diagnosed with neurosyphilis and the other, with hydrocephalus) after proper treatment. Partial recovery was treatment's outcome of treatment in 10 patients (nine with neurosyphilis and one with subdural hematoma). In two individuals (one with alcoholic dementia and the other with hydrocephalus) specific treatment for the etiology of dementia was not indicated, and in follow up they were cognitively stable. Eight cases were lost on follow-up.

\section{DISCUSSION}

The prevalence of potentially reversible dementias in this sample, at $8 \%$, is similar to the one found in a previous study by our group ${ }^{7}$. A remark should be made regarding the fact that, in contrast to the present study, the previous study had no did not include one cases of alcoholism (out of one hundred) as a reversible etiology for dementia., opposed to this one. Alcoholic dementia has been a subject of discussion as to its actual reversibility ${ }^{18}$. In spite of this, it could fit within the concept of potentially reversible causes of dementia, and therefore it was included in this study. The results obtained in this article are also consistent with the prevalence range for potentially reversible dementias assessed by previous studies $^{18,19}$, between 0 and $30 \%$.

The most frequent diagnoses for potentially reversible cases were neurosyphilis and hydrocephalus. In past studies ${ }^{2-4}$ depression and drug intoxication were the most frequent diagnoses for such cases. Nonetheless, depression was not considered a reversible dementia in this study. A prevalence study based on a tertiary hospital dementia outpatient clinic population is subject to a selection bias, which is basically a consequence of the local health system structure and the community from which the cases are drawn, and therefore, this kind of study is a unique reflection of the groups' experience. For instance, neurosyphilis was found to be the most frequent etiology for potentially reversible dementia in this particular study. However, this diagnosis haswas not been observed in previous series, including other Brazilian prevalence studies ${ }^{9,12}$. This notwithstanding, prevalence studies such as the present, prove importance not only for the reasons previously reported, but also for contributing towards establishing a ground for epidemiological data regarding potentially reversible dementias ins among developing countries, from which data remain are still scarce, It has been suggested that there is a higher prevalence of potentially reversible dementias among individuals aged less than 65 years ${ }^{20}$. Indeed, in the present study a significant difference in age distribution between the potentially reversible dementia group (which had lower median for age) and the irreversible dementia group was found. This finding could signify that some potentially reversiblecases of dementia, such as neurosyphilis, are more prevalent among a younger population, while primary dementias such as AD haves a progressively higher incidence, the older the population is ${ }^{21}$.

Alzheimer's disease was the most frequent diagnosis for the dementia syndrome in the sample here considered here. The prevalence found of $59.6 \%$ is also consistent with previous series. Marsden \& Harrison ${ }^{11}$ described a prevalence of presumed $A D$ of $57.1 \%$. Nitrini et al $^{7}$ reported $54 \%$ of AD diagnosis in 100 outpatients, as well as $20 \%$ of prevalence for vascular dementia. Clarfield ${ }^{3}$, reviewing 32 studies that investigated the prevalence of dementias, found out that Alzheimer's disease was diagnosed in $56.8 \%$ of the cases, while. Ames et al. ${ }^{6}$ had 59 out of 100 cases diagnosed with $A D$.

Among patients with potentially reversible dementias, two had a full recovery and 10 had partial recovery after treatment, representing $9 \%$ with full recovery and $45.4 \%$ with partial recovery. Considering the data discussed above, these findings do not lie within the range found in previous studies. It must be taken into account that in the present sample, unlike other studies, neurosyphilis was the most frequent diagnosis among potentially reversible causes of dementia (as well as the leading diagnosis among patients in which full or partial recovery was observed), which could providebean explanation for the discrepancy found here.

The prevalence of neurosyphilis cases found, should also point out the importance of syphilis serology as one ofamong the tests that should be included in the laboratory evaluation of dementia. Although its prevalence has fallen over the past years, neurossyphilis is still a relevant cause for potentially reversible dementia, as it can be observed from the results of this study, and should not be overlooked as a diagnosis, especially in among populations of developing countries populations.

Among the patients who were evaluated in our outpatient clinic, the cognitive impairment was attributed to depression in 31 individuals (6.9\%). The significance of ascertaining the prevalence of depres- 
sion in a dementia outpatient clinic is enhanced by the fact that it has been proposed ${ }^{22}$ that patients suffering from depression along with a coexisting cognitive impairment ("reversible dementia"), are more prone to developing irreversible dementia on follow-up, than patients with depression alone. Accordingly, this population warrants an attentive follow-up.

\section{REFERENCES}

1. Maletta GJ. The concept of "reversible" dementia: how nonreliable terminology may impair effective treatment. J A m Geriatr Soc 1990;38:136-140

2. Barry PP, Moskowitz MA. The diagnosis of reversible dementia in the elderly: a critical review. Arch Intern Med 1988;148:1914-1918.

3. Clarfield AM. The reversible dementias: do they reverse? Ann Intern Med 1988;109:476-486.

4. Weytingh MD, Bossuyt PMM, van Crevel H. Reversibledementia: more than $10 \%$ or less than $1 \%$ ? J N eurol 1995;242:466-471.

5. Freter S, Bergman H, Gold S, Chertkow H, Clarfield AM. Prevalence of potentially reversible dementias and actual reversibility in a memory clinic cohort. CMAJ 1998;159:657-662.

6. AmesD, Flicker L, HelmeRD. A memory dinicatageriatrichospital:rationale, routineand results froorm thefirst 100 patients. Med J Aust 1992;156:618-622.

7. Nitrini R, Mathias SC, Caramelli $P$, et al. Evaluation of 100 patients with dementia in São Paulo, Brazil: correlation with socioeconomic status and education. Alzheimer Dis Assoc Disord 1995:146-151.

8. WalstraGJM, TeunisseS, van Gool WA, van Crevel H. Reversibledementia in elderly patients referred to a memory dinic. J Neurol 1997;244:17-22.
9. ValeFAC, Miranda SJC. Clinical and demographic features of patients with dementia attended in a tertiary outpatient clinic. Arq NeuroPsiquiatr 2002;60:548-552.

10. Hejl A, Hogh P, Waldemar G. Potentially reversible conditions in 1000 consecutive memory clinic patients. J Neurol Neurosurg Psychiatry 2002;73:390-394.

11. Marsden CD, Harrison MJG. Outcome of investigation of patients with presenile dementia. Br Med J 1972;2:249-252.

12. Cunha UGV. An investigation of dementia among el derly outpatients Acta Psychiatr Scand 1990;82:261-263.

13. Diagnostic and Statistical Manual of Psychiatric Disorders 4.Ed. (DSMIV) Washington DC: APA, 1994.

14. McKhann G, Drachman D, Folstein M, Katzman R, PriceD, Stadlan EM. Clinical diagnosis of Alzheimer's disease. Neurology 1984;34:939-944.

15. Roman GC, Tatemichi TK, Erkinjuntti T, et al. Vascular dementia: diagnostic criteria for research studies. Neurology 1993;43:250-260.

16. McKeith IG, Galasko D, Kosaka K, et al. Consensus guidelines for the clinical and pathological diagnosis of dementia with Lewy bodies (DLB): report of the Consortium on DLB international workshop. Neurology 1996;47:1113-1124.

17. The Lund and Manchester Group. Clinical and neuropathological criteria for frontotemporal dementia. J Neurol Neurosurg Psychiatry 1994;57:416-418.

18. A rnold SE, Kumar A. Reversible Dementias. Med Clin N Am 1993; 77:215-230

19. Piccini C, Bracco L, Amaducci L. Treatable and reversible dementias: an update. J Neurol Sci 1998;153:172-181.

20. Smith JS, Kiloh LG. The investigation of dementia: results in 200 consecutive admissions. Lancet 1981;1:824-827.

21. Herrera E Jr, Caramelli P, Silveira AS, Nitrini R. Epidemiologic survey of dementia in a community-dwelling Brazilian population. Alzheimer Dis Assoc Disord 2002;16:103-108.

22. AlexopoulosGS, Meyers BS, Young RC, MattisS, KakumaT. Thecourse of geriatric depression with "reversible dementia": a controlled study. Am J Psychiatry 1993;150:1693-1699. 